\title{
Increased induction of apoptosis by Propionibacterium freudenreichii TL133 in colonic mucosal crypts of human microbiota-associated rats treated with 1,2-dimethylhydrazine
}

\author{
Annaïg Lan ${ }^{1,2}$, Aurélia Bruneau ${ }^{3}$, Martine Bensaada ${ }^{3}$, Catherine Philippe ${ }^{3}$, Pascale Bellaud ${ }^{4}$, \\ Sylvie Rabot ${ }^{3}$ and Gwénaël Jan $^{1} *$ \\ ${ }^{1}$ INRA, Agrocampus Rennes, UMR1253 Science et Technologie du Lait et de l'Oeuf, Rennes F-35000, France \\ ${ }^{2}$ Laboratoires Standa, Caen F-14050, France \\ ${ }^{3}$ INRA, UR910 Ecologie et Physiologie du Système Digestif, Jouy-en-Josas F-78350, France \\ ${ }^{4}$ Laboratoire d'Anatomie Pathologique, Faculté de Médecine, Université de Rennes 1, Rennes F-35000, France \\ (Received 13 November 2007 - Revised 10 March 2008 - Accepted 11 March 2008 - First published online 9 May 2008)
}

Propionibacterium freudenreichii, a food-grade bacterium able to kill colon cancer cell lines in vitro by apoptosis, may exert an anticarcinogenic effect in vivo. To assess this hypothesis, we administered daily $2 \times 10^{10}$ colony-forming units (CFU) of $P$. freudenreichii TL133 to human microbiota-associated (HMA) rats for $18 \mathrm{~d}$. Either saline or 1,2-dimethylhydrazine (DMH) was also administered on days 13 and 17 and rats were killed on day 19. The levels of apoptosis and proliferation in the mid and distal colon were assessed by terminal deoxynucleotide transferase-mediated deoxyuridine triphosphate nick end labelling (TUNEL) and proliferating cell nuclear antigen (PCNA) immunolabelling, respectively. The administration of $P$. freudenreichii TL133 significantly increased the number of apoptotic cells in DMH-treated rats compared to those given DMH only $(P<0 \cdot 01)$. Furthermore, propionibacteria were able to decrease the proliferation index in the distal colon after treatment with DMH $(P<0 \cdot 01)$. Conversely, propionibacteria alone did not exert such an effect on healthy colonic mucosa. $P$. freudenreichii TL133 thus facilitated the elimination of damaged cells by apoptosis in the rat colon after genotoxic insult and may play a protective role against colon cancer.

Probiotics: Colon carcinogenesis: Apoptosis: Gnotobiotic rats

Colon cancer constitutes a growing health concern in developed countries. Indeed, it is one of the major causes of death by cancer in the Western world. It is the third most frequent cancer in men, after prostate and lung, and the second most common in women, after breast. The increased incidence of this disease is likely to be linked with following a Western lifestyle, in particular the Western diet and physical inactivity $^{(1,2)}$. An appropriate diet may prevent three out of four cases of colorectal cancer ${ }^{(3)}$. Because colon cancer is thus a preventable disease, the impact of food components on carcinogenesis of the colon has been investigated in a considerable number of studies during the last few decades. In particular, there has been a growing interest in the ability of probiotics to inhibit the development of cancer. A probiotic is generally defined as 'a live microorganism which, when administered in adequate amounts, confers a health benefit to the host ${ }^{(4)}$. Previous studies have established that the ingestion of certain strains of bifidobacteria or lactobacilli, either alone or in combination with a prebiotic, reduces the incidence of tumour and/or colonic pre-neoplastic lesions, aberrant crypt foci, in animals treated with carcinogens ${ }^{(5-10)}$. However, the precise mechanisms by which probiotics act on the colonic mucosa are still unclear ${ }^{(11)}$. Possible mechanisms by which probiotics could have anti-cancer effects include an enhancement of the host's immune response, the binding or degrading of potential carcinogens, the production of antitumourigenic compounds, the alteration of the intestinal microbiota and its metabolic activities, or the alteration of physiological conditions in the colon, for instance $\mathrm{pH}$ or the concentration and profile of bile acids ${ }^{(12-14)}$.

Certain food components might be considered as having a preventive effect against colon cancer by favouring the apoptotic depletion of DNA-damaged cells which might be likely to progress to malignancy. Acquired resistance towards apoptosis is a hallmark of cancer ${ }^{(15)}$ and progressive inhibition of apoptosis is thought to be an integral component of the genesis of colorectal adenoma and carcinomas ${ }^{(16-18)}$. Furthermore, a severe imbalance of proliferation/apoptosis, characterised by an increase in the proliferation of cells and a decrease in apoptosis, was reported in the colon of human subjects with a history of large adenomas ${ }^{(19)}$. Therefore, dietary factors which increase apoptosis above levels induced by the carcinogen

Abbreviations: CFU, colony-forming units; DMH, 1,2-dimethylhydrazine; HMA, human microbiota-associated; PAB, propionic acid bacteria/propionibacteria; PCNA, proliferating cell nuclear antigen; TUNEL, terminal deoxynucleotide transferase-mediated deoxyuridine triphosphate nick end labelling.

* Corresponding author: Dr Gwénaël Jan, fax +332234853 50, email gwenael.jan@rennes.inra.fr 
may reduce the probability of cancer development ${ }^{(20)}$. So far, only a few dietary compounds such as the glucosinolate sinigrin, $n$-3 PUFA, chicory fructans, or resistant starch combined with Bifidobacterium lactis, have been reported to be able to facilitate elimination of damaged cells by apoptosis in rat colon between 6 and $72 \mathrm{~h}$ after genotoxic insult induced by a carcinogen ${ }^{(20-23)}$.

The pro-apoptotic potential of dairy propionibacteria (PAB) was here investigated in vivo. Several species, including Propionibacterium freudenreichii probiotic strain SI41, have previously been shown to kill human colon adenocarcinoma cells in vitro ${ }^{(24)}$. They induce apoptosis via their metabolites, one of which is propionate, that acts on cancer cells and leads to cell cycle arrest in the $\mathrm{G} 2 / \mathrm{M}$ phase, generation of reactive oxygen species, Bax translocation, mitochondrial depolarisation, activation of caspases, and chromatin condensation and fractionation ${ }^{(24,25)}$. Their ability to do so confers them anti-cancer potential. However, the specificity of induction of apoptosis has not yet been characterised, and doing so is crucial, for ideally only malignant cells should be killed and not healthy ones. The occurrence of such a process in vivo has yet to be demonstrated. We have recently shown that certain strains of $P$. freudenreichii, including TL133, are able to survive and to be metabolically active in the gastrointestinal tract of HMA rats ${ }^{(26)}$. This strain also produces metabolites that induce colon cancer cell apoptosis in vitro. We thus investigated the pro-apoptotic effect of TL133 at an early stage of carcinogenesis. Colonic epithelial apoptosis and proliferation were quantified in HMA rats consuming TL133 on a daily basis, $48 \mathrm{~h}$ after the induction of carcinogenesis with 1,2-dimethylhydrazine (DMH).

\section{Materials and methods}

\section{Chemicals}

When not specified, chemicals were purchased from SigmaAldrich (Saint-Quentin-Fallavier, France).

\section{Bacterial strain}

P. freudenreichii subsp. shermanii strain TL133 was kindly provided by Laboratoires Standa (Caen, France) as a freezedried powder in sealed pots which contained approximately $4 \times 10^{11}$ colony-forming units $(\mathrm{CFU}) / \mathrm{g}$ to be used in the present study. The bacterial cells were kept at $-20^{\circ} \mathrm{C}$ until the moment of use. Before their administration to rats, the powdered bacterial cells were dispersed in $20 \mathrm{ml}$ of sterile saline (Aguettant, Alcyon, Paris, France) and gently stirred until a homogeneous suspension was achieved. The final concentration of the bacterial suspension was $2 \times 10^{10} \mathrm{CFU} / \mathrm{ml}$.

\section{Animals and diet}

Male Fischer 344 rats ( $n$ 24), aged 2 months at the start of the experiment (mean weight $208 \pm 3 \mathrm{~g}$ ), were used. They were born germ-free and bred in germ-free conditions in the Germ-Free Rodent Breeding Facilities of UR910 Ecologie et Physiologie du Système Digestif (INRA, Jouy-en-Josas, France), according to previously established methods ${ }^{(27)}$. Throughout the study, animals were housed in sterile Plexiglas isolators (Ingénia, Vitry-sur-Seine, France) maintained in a controlled light-dark cycle (lights on from 07.00 to 19.00 hours), at a controlled temperature $\left(20-22^{\circ} \mathrm{C}\right)$ and humidity $(45-55 \%)$. They were given free access to sterilized tap water and to a pelleted semi-synthetic diet (SAFE, Augy, France) sterilized by $\gamma$-irradiation at $45 \mathrm{kGy}$ (IBA Mediris, Fleurus, Belgium). In order to reproduce the diversity of a human-type diet, lipids and proteins of both animal and plant origins, as well as saccharose and cooked starch, were included. The diet consisted of $29 \%(\mathrm{w} / \mathrm{w})$ mashed potato, $29 \%$ maize starch, $5 \%$ saccharose, $5 \%$ casein, $12 \%$ soya isolate (Nurish 1500, DuPont Protein Technologies, Paris, France), $3 \%$ maize oil, $3 \%$ lard, $0.015 \%$ cholesterol, $6 \%$ cellulose, and $8 \%$ mineral and vitamin additives ${ }^{(26)}$. Analytical compounds of DM were crude proteins $18 \%$, crude fat $8 \%$, ash $6 \%$ and carbohydrates $68 \%$ (energy $19.33 \mathrm{MJ} / \mathrm{kg} \mathrm{DM}$; Eurofins Scientific Analytics, Nantes, France). Food intake and body weight were recorded weekly and at death. All procedures were carried out in accordance with the European guidelines for the care and use of laboratory animals and with permission 78-58 of the French Veterinary Services to use rats for this type of experiment.

At the start of the experiment, all rats were orally administered $1 \mathrm{ml}$ fresh faecal suspension made from the stools of a healthy adult human subject. This subject had followed a normal diet for 3 weeks but excluded the ingestion of fermented products containing PAB. Fresh stools $(2 \mathrm{~g})$ were transferred to an anaerobic glove box and dispersed in $200 \mathrm{ml}$ brain heart infusion broth (Difco, Becton Dickinson, Le Pont de Claix, France). The suspension was subsequently transferred to the isolators and administered to the rats using a sterile stainless-steel stomach tube. Then 3 weeks were given to allow the microbiota to settle in the digestive tract and the rats' physiology to adapt to the new bacterial status.

\section{Experimental design}

The HMA rats were randomly allocated into four groups, namely $\mathrm{PAB}-\mathrm{DMH}-, \mathrm{PAB}+\mathrm{DMH}-, \mathrm{PAB}-\mathrm{DMH}+$ and $\mathrm{PAB}+\mathrm{DMH}+$, which were housed in four distinct isolators (six animals per group, two animals per cage). Rats assigned to the $\mathrm{PAB}+$ groups were gavaged daily for $18 \mathrm{~d}$ with $2 \times 10^{10}$ CFU PAB suspended in $1.0 \mathrm{ml}$ physiological saline, while $\mathrm{PAB}-$ groups received $1.0 \mathrm{ml}$ physiological saline alone. On day 13 of PAB administration, animals received by oral gavage either two doses of DMH $(25 \mathrm{mg} / \mathrm{kg}$ body weight dissolved in physiological saline as described previously ${ }^{(28,29)}$ ) $4 \mathrm{~d}$ apart (DMH+ groups), or two sham administrations of physiological saline (DMH - groups). DMH was given $4 \mathrm{~h}$ after $\mathrm{PAB}$ gavage to avoid a possible direct interaction between $\mathrm{PAB}$ and carcinogen during the bolus transit. All rats were killed by $\mathrm{CO}_{2}$ asphyxiation $48 \mathrm{~h}$ after the second DMH administration. The caecum was removed, the caecal $\mathrm{pH}$ was measured and the content was weighed. One aliquot of caecal content was used immediately for enumeration of $\mathrm{PAB}$ and the remaining part was distributed into several vials stored at $-80^{\circ} \mathrm{C}$ for SCFA analysis. The colon was removed intact by excision at the caeco-colonic junction and at the pelvis and gently flushed with PBS (pH 7.4) to remove residual bowel contents. The colon was divided into three parts of equal length, namely 
proximal, mid and distal. Tissue samples ( $8 \mathrm{~mm}$ long) were excised from distal and mid parts ${ }^{(29)}$ and fixed for $24 \mathrm{~h}$ in $4 \%$ formalin for analysis of apoptotic and proliferation levels in the crypt epithelium as described later.

\section{Enumeration of propionibacteria in intestinal samples}

Freshly collected faeces (before the beginning of PAB administration and $1 \mathrm{~d}$ before killing) and caecal contents were immediately dispersed in a dilution medium (casein enzymatic hydrolysate $2 \mathrm{~g} / \mathrm{l}$, yeast extract $2 \mathrm{~g} / \mathrm{l}, \mathrm{NaCl} 5 \mathrm{~g} / \mathrm{l}, \mathrm{KH}_{2} \mathrm{PO}_{4} 1 \mathrm{~g} / \mathrm{l}$, $\mathrm{pH} 7.0)$, and $1.0 \mathrm{ml}$ of this $10-$ fold $(\mathrm{w} / \mathrm{v})$ suspension was used for enumeration of PAB. Samples from serial 10-fold dilutions were poured into Pal-Propiobac ${ }^{\circledR}$ selective agar (Laboratoires Standa) with added metronidazole $(4 \mathrm{mg} / \mathrm{l})$ for the enumeration of PAB in samples of intestinal origin, as described previously ${ }^{(30)}$. Plates were then incubated anaerobically at $30^{\circ} \mathrm{C}$ for 1 week prior to colony counting. Results were expressed as $\log \mathrm{CFU} / \mathrm{g}$ faeces or caecal content.

\section{SCFA analysis in caecal samples}

Samples were water-extracted and proteins were precipitated with phosphotungstic acid. A volume of $0 \cdot 1 \mu \mathrm{l}$ of the supernatant was analysed as to SCFA on a gas-liquid chromatograph (Autosystem XL; Perkin Elmer, Saint-Quentin-en-Yvelines, France) equipped with a split-splitless injector, a flame-ionisation detector and a capillary column $(15 \mathrm{~m} \times 0.53 \mathrm{~mm}, 0.5 \mu \mathrm{m})$ impregnated with SP 1000 (FSCAP Nukol; Supelco, SaintQuentin-Fallavier, France). Carrier gas (He) flow rate was $10 \mathrm{ml} / \mathrm{min}$ and inlet, column and detector temperatures were 175,100 and $280^{\circ} \mathrm{C}$, respectively. 2-Ethylbutyrate was used as the internal standard ${ }^{(31)}$. Samples were analysed in duplicate. Data were collected and peaks integrated using the Turbochrom v6 software (Perkin Elmer, Courtaboeuf, France).

\section{Assessment of crypt cell apoptosis}

Apoptosis was evaluated by the terminal deoxynucleotide transferase-mediated deoxyuridine triphosphate nick end labelling (TUNEL) method using the In situ Cell Death Detection Kit (Roche Diagnostics, Penzberg, Germany). This method allows for the detection and quantification of apoptotic cells, based on labelling of DNA strand breaks generated during apoptosis $^{(32)}$. Sections ( $3 \mu \mathrm{m}$ thick) from paraffin-embedded colons were mounted on electrostatic-treated slides (Superfrost ${ }^{\circledR}$ Plus; VWR, Fontenay-sous-Bois, France). Sections were then deparaffinised with toluene, hydrated through a graded series of ethanol in distilled water and treated with proteinase K (Roche, Mannheim, Germany) for $15 \mathrm{~min}$ to permeabilise tissues. Endogenous peroxidase activity was blocked by treatment with $10 \%$ hydrogen peroxide for $10 \mathrm{~min}$ at $37^{\circ} \mathrm{C}$ in a humid chamber. After washes in PBS, the TUNEL solution (fluorescein-labelled nucleotides and terminal deoxynucleotidyl transferase; In situ Cell Death Detection Kit) was applied to all sections except to negative controls, samples were covered with coverslips and the sections were incubated for $1 \mathrm{~h}$ at $37^{\circ} \mathrm{C}$. Converter solution (antifluorescein antibody conjugated with horseradish peroxidase; In situ Cell Death Detection Kit) was applied for $30 \mathrm{~min}$ at $37^{\circ} \mathrm{C}$. Finally, diaminobenzidine solution (Vector
Laboratories, Burlingame, CA, USA) was applied for $3 \mathrm{~min}$. After two washes in PBS the sections were counterstained with Mayer's haematoxylin for $2 \mathrm{~min}$ and rinsed for $2 \mathrm{~min}$ in running tap water before dehydration and coverslip mounting.

The TUNEL-stained cells were blindly counted in mid and distal colonic sections within longitudinally well-oriented crypts (i.e. from the bottom to the top of the crypt). Twenty randomly chosen intact crypts were scored per colonic region per rat (120 crypts per colonic region per group) under a light microscope (magnification $\times 100$ ), in order to distinguish apoptotic from necrotic cells by cell morphology analysis. Data were expressed as numbers of apoptotic cells per crypt. Moreover, the number and position of the TUNELlabelled cells along the crypts were specifically examined in the $\mathrm{DMH}+$ rats; each crypt was divided into three equal zones, namely lower, mid and upper zones, and forty randomly chosen intact crypts were scored per colon region per rat (240 crypts per colon region per DMH+ group).

\section{Proliferative activity in the colonic mucosa}

Proliferative activity in the colonic mucosa was evaluated by determining proliferating cell nuclear antigen (PCNA) immunoreactivity in sections from paraffin-embedded colons ${ }^{(33)}$. Sections $(3 \mu \mathrm{m}$ thick) of paraffin-embedded colons were mounted on electrostatic-treated slides (Superfrost ${ }^{\circledR}$ Plus). Sections were then deparaffinised with toluene and hydrated through a graded series of ethanol in distilled water. To unmask PCNA protein, tissue sections were immersed in citric acid buffer, pH 6.0 (Dako REAL Target Retrieval Solution; Dako, Glostrup, Denmark) for $40 \mathrm{~min}$. The slides were washed twice in PBS containing $0.05 \%$ Tween 20, treated for $10 \mathrm{~min}$ in $10 \%$ hydrogen peroxide to block endogenous peroxidase and rinsed with PBS. The slides were then incubated for $30 \mathrm{~min}$ at room temperature in a humid chamber with the primary antibody (anti-PCNA mouse monoclonal; Interchim, Montluçon, France) diluted 1:300 in PBS. The slides were rinsed twice in PBS and covered with a biotinylated 'universal' secondary antibody (RTU Vectastain Universal Elite ABC Kit; Vector Laboratories). Immunohistochemical staining was performed in a humid chamber for $30 \mathrm{~min}$ using the avidin-biotin immunoenzymatic antigen detection system (RTU Vectastain Universal Elite ABC Kit). After this period slides were rinsed twice in PBS and covered with diaminobenzidine solution for $10 \mathrm{~min}$ to develop labelling. The slides were then counterstained with Mayer's haematoxylin, and rinsed for $2 \mathrm{~min}$ in running tap water before dehydration and coverslip mounting.

The number of PCNA-positive cells (only cells with dark brown-stained nuclei were considered PCNA-positive ${ }^{(34)}$ ) and the total number of cells per crypt (i.e. number of cells from the bottom to the top of the crypt appearing in the section) were counted in twenty longitudinally well-oriented and visible entire crypts per colonic region (mid and distal colonic sections) under a light microscope (magnification $\times 100$ ). The samples were evaluated in a blind manner as to avoid bias. Proliferative activity was calculated as the mean number of PCNA-positive cells divided by the mean number of total cells multiplied by 100 . 


\section{Statistical analysis}

The experiment was analysed as a $2 \times 2$ factorial design, using a two-way ANOVA. The terms analysed as treatments in the ANOVA model were PAB, DMH and $\mathrm{PAB} \times \mathrm{DMH}$. Where ANOVA indicated significant effects, paired means were compared using the Student-Newman-Keuls post hoc test. Statistical significance was set at $P<0.05$. Calculations were performed using the Statview ${ }^{\circledR}$ software, version 5.0 (SAS Institute, Cary, NC, USA). All data are expressed as mean values with their standard errors $(n 6)$

\section{Results}

\section{General observations}

No observable difference in the rats' health status was noticed during the experiment. The administration of PAB had no significant effect on body weight gain between animal groups of the same experiment (78 (SEM 1) g/rat). Thus, the rats' body weight was similar among groups by the end of the experiments (285 (SEM 3) g).

\section{Propionibacteria survival in the gastrointestinal tract}

Dairy PAB were undetectable on selective medium in the faeces of all rats at the beginning of the experiment. In the $\mathrm{PAB}$ - groups, they remained undetected throughout the entire experiment. In the $\mathrm{PAB}+$ groups, the faecal concentration of $\mathrm{PAB}$ reached 7.75 (SEM 0.06) log CFU/g after $15 \mathrm{~d}$ of consumption of $P$. freudenreichii TL133 at a dose of $10.3 \log \mathrm{CFU} / \mathrm{rat}$ per $\mathrm{d}$. Three days later, at the time of killing, the caecal concentration of $\mathrm{PAB}$ was 6.86 (SEM 0.07) $\log$ CFU/g caecal content.

\section{Caecal fermentation variables}

No significant difference in caecal $\mathrm{pH}$ was observed between $\mathrm{PAB}-$ and $\mathrm{PAB}+$ groups, whether the rats were treated or not with the chemical carcinogen (Table 1). With regard to SCFA, no significant difference was detected between groups. We observed a slight but non-significant increase in the relative proportions of propionate and valerate in the $\mathrm{PAB}+\mathrm{DMH}+$ group compared to the $\mathrm{PAB}-\mathrm{DMH}+$ group.

\section{Effect of Propionibacterium freudenreichii TL133 on the colonic mucosa}

Oral dosing with PAB and/or with the carcinogen DMH did not induce any significant difference in the number of total cells per crypt across the entire colon. The mean number of cells counted in randomly chosen crypts of whole colons (forty crypts counted per rat, six per group) was 59.1 (SEM $0 \cdot 8)$ cells. No variation of crypt length was thus shown, allowing for the comparison of groups in terms of apoptotic and proliferative activities.

Effect of Propionibacterium freudenreichii TL133 on colonocyte apoptosis

While apoptosis mainly occurred in the upper crypt zone in healthy colons ( $\mathrm{DMH}-$ rats), apoptotic events were observed in the entire length of crypts, including the proliferative and the differentiation zones, when rats were treated with DMH. Examples of crypts observed in the distal colon are shown in Fig. 1 (A). No characteristic feature of necrosis was observed in the crypts, regardless of the colonic region and of the rat group.

Table 1. Effect of Propionibacterium freudenreichii TL133 supplementation on the caecal $\mathrm{pH}$, SCFA concentrations and relative proportions of the SCFA*

(Mean values with their standard errors for six rats per group)

\begin{tabular}{|c|c|c|c|c|c|c|c|c|}
\hline & \multicolumn{4}{|c|}{$\mathrm{DMH}-$} & \multicolumn{4}{|c|}{$\mathrm{DMH}+$} \\
\hline & \multicolumn{2}{|c|}{ PAB- } & \multicolumn{2}{|c|}{$\mathrm{PAB}+$} & \multicolumn{2}{|c|}{ PAB - } & \multicolumn{2}{|c|}{$\mathrm{PAB}+$} \\
\hline & Mean & SEM & Mean & SEM & Mean & SEM & Mean & SEM \\
\hline Caecal pH & $6 \cdot 81$ & 0.07 & $6 \cdot 71$ & 0.05 & $6 \cdot 64$ & 0.06 & $6 \cdot 80$ & 0.05 \\
\hline \multicolumn{9}{|c|}{ SCFA concentration $(\mu \mathrm{mol} / \mathrm{g})$} \\
\hline Acetate & $19 \cdot 08$ & 1.45 & $19 \cdot 38$ & $2 \cdot 16$ & $19 \cdot 41$ & 0.99 & $18 \cdot 42$ & 1.42 \\
\hline Propionate & 3.50 & $0 \cdot 21$ & 3.52 & 0.23 & 3.53 & $0 \cdot 21$ & 3.71 & 0.27 \\
\hline Butyrate & $2 \cdot 28$ & 0.27 & $2 \cdot 22$ & 0.28 & $2 \cdot 59$ & 0.35 & $2 \cdot 16$ & 0.35 \\
\hline Valerate & 0.13 & 0.01 & 0.09 & 0.03 & 0.09 & 0.01 & $0 \cdot 14$ & 0.01 \\
\hline Caproate & 0.08 & 0.02 & 0.08 & 0.02 & 0.08 & 0.03 & 0.07 & 0.01 \\
\hline BCFA & 0.53 & 0.04 & 0.42 & 0.06 & 0.46 & 0.03 & 0.53 & 0.02 \\
\hline Total SCFA & $25 \cdot 61$ & 1.80 & $25 \cdot 72$ & 2.45 & $26 \cdot 15$ & 1.39 & $25 \cdot 02$ & 2.03 \\
\hline \multicolumn{9}{|c|}{ Relative SCFA proportion (\%) } \\
\hline Acetate & 74.37 & 0.79 & $74 \cdot 79$ & $2 \cdot 04$ & $74 \cdot 33$ & 1.49 & $73 \cdot 73$ & 0.45 \\
\hline Propionate & $13 \cdot 80$ & 0.63 & $14 \cdot 12$ & $1 \cdot 26$ & $13 \cdot 47$ & 0.38 & $14 \cdot 89$ & 0.37 \\
\hline Butyrate & $8 \cdot 89$ & 0.85 & 8.56 & 0.52 & $9 \cdot 77$ & $1 \cdot 10$ & $8 \cdot 37$ & 0.72 \\
\hline Valerate & 0.52 & 0.04 & 0.42 & 0.16 & 0.34 & 0.02 & 0.56 & 0.07 \\
\hline Caproate & 0.32 & 0.07 & 0.37 & 0.13 & 0.29 & 0.09 & 0.27 & 0.03 \\
\hline BCFA & $2 \cdot 10$ & 0.12 & 1.74 & 0.32 & 1.79 & 0.16 & $2 \cdot 18$ & 0.20 \\
\hline
\end{tabular}


(A)

$\mathrm{MH}-$
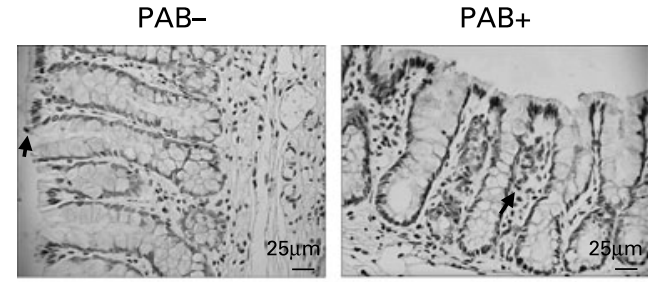

$\mathrm{DMH}+$
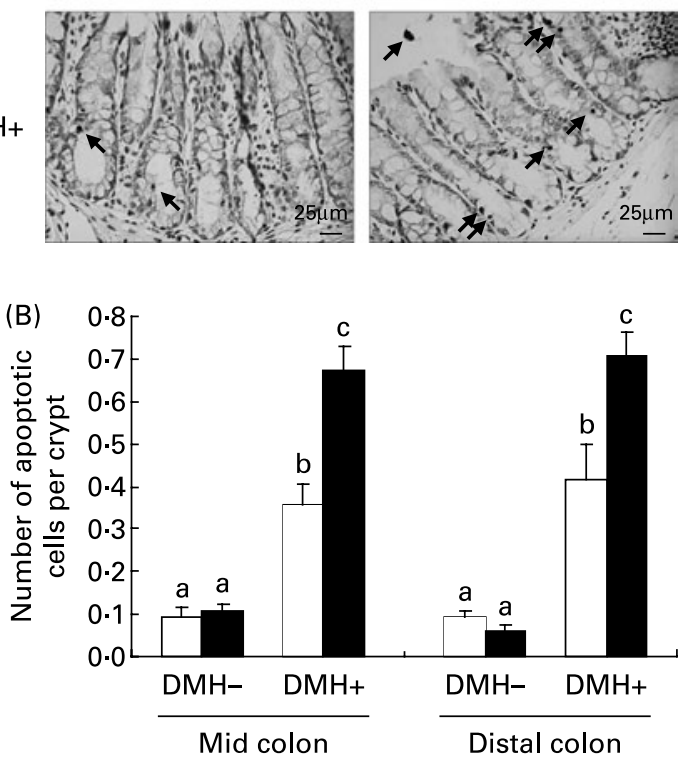

Fig. 1. Detection and quantification of apoptotic cells in terminal deoxynucleotide transferase-mediated deoxyuridine triphosphate nick end labelling (TUNEL) and haematoxylin-stained sections of human microbiota-associated rat colon. $(A)$, Apoptotic cells $(\rightarrow)$ detected in distal colon crypts of rats supplemented with propionibacteria $(\mathrm{PAB}+)$ or not $(\mathrm{PAB}-), 48 \mathrm{~h}$ after 1,2-dimethylhydrazine $(\mathrm{DMH}+)$ or saline administration $(\mathrm{DMH}-)$ (light microscope, magnification $\times 40$ ). (B), Quantification of apoptotic cells per crypt (twenty crypts counted per colon region of each rat; $n 6$ ) from mid and distal colon of the same rats $(\mathbf{\square}, \mathrm{PAB}+; \square, \mathrm{PAB}-)$. Values are means with their standard errors depicted by vertical bars. Apoptosis was negligible in $\mathrm{DMH}-$ groups in both regions of the colon. Propionibacterium freudenreichii TL133 consumption resulted in a significant increase of the apoptosis level, both in mid and distal colons, among the $\mathrm{DMH}+$ groups. ${ }^{\mathrm{a}, \mathrm{b}, \mathrm{c}}$ Within each colon region, values with unlike superscript letters were significantly different (ANOVA and Student-Newman-Keuls test; $P<0.01$ ).

The administration of $P$. freudenreichii TL133 alone did not increase the number of apoptotic cells in healthy colonic mucosa, as shown in Fig. 1 (B). Indeed, the number of apoptotic cells per crypt in the $\mathrm{PAB}+\mathrm{DMH}-$ group was close to that of basal apoptotic level (PAB-DMH - group), both in mid and distal colon. The number of apoptotic events per crypt was 0.09 (SEM 0.02) in both colon regions of the $\mathrm{PAB}-\mathrm{DMH}-$ group, and ranged from 0.06 (SEM 0.02) in the distal colon to 0.11 (SEM 0.02) in the mid colon of the $\mathrm{PAB}+\mathrm{DMH}-$ group. Thus, $\mathrm{PAB}$ supplementation did not modify the apoptotic cell number in healthy colonic mucosa. Conversely, oral administration of DMH increased the number of apoptotic cells per crypt from 0.09 (SEM 0.02) in the whole colon to 0.36 (SEM 0.05) and 0.42 (SEM 0.08) in the mid and distal colons, respectively. Administration of PAB further raised these apoptotic cell numbers up to 0.68 (SEM 0.05) and 0.71 (SEM 0.05) in the mid $(P<0.01)$ and distal $(P<0 \cdot 01)$ colons, respectively.
In order to determine in which crypt zone $\mathrm{PAB}$ administration induced apoptosis of DMH-damaged cells, the crypts were divided in three equal zones (lower, middle and upper) and apoptotic events were counted. Fig. 2 shows the spatial distribution of apoptotic cells in crypts of the mid (A) and distal (B) colon of $\mathrm{DMH}+$ rats. The administration of PAB increased the number of apoptotic events in all crypt zones of both colon regions, especially in the middle crypt zone where apoptotic activity was maximal compared to its $\mathrm{PAB}$ - counterpart. In the mid colon, the induction of apoptosis by PAB was more efficient in the middle and upper crypt zones than in the lower zone. In this region of the colon, 0.38 (SEM 0.02) apoptotic cells were found in the middle crypt zone of $\mathrm{PAB}+\mathrm{DMH}+$ rats $v .0 .21$ (SEM 0.02) in $\mathrm{PAB}-$ counterparts $(P<0.01)$. In the distal colon, the induction of apoptosis by $\mathrm{PAB}$ was increased in all crypt zones, especially in the middle crypt zone in which 0.39 (SEM 0.06) apoptotic cells were counted $v .0 .13$ (SEM 0.02) in the $\mathrm{PAB}-\mathrm{DMH}+$ group $(P<0 \cdot 01)$.

Effect of Propionibacterium freudenreichii TL133 on the proliferative activity of colonocytes

In order to assess the effect of $P$. freudenreichii TL133 on the proliferation of crypt cells, we scored the PCNA labelling
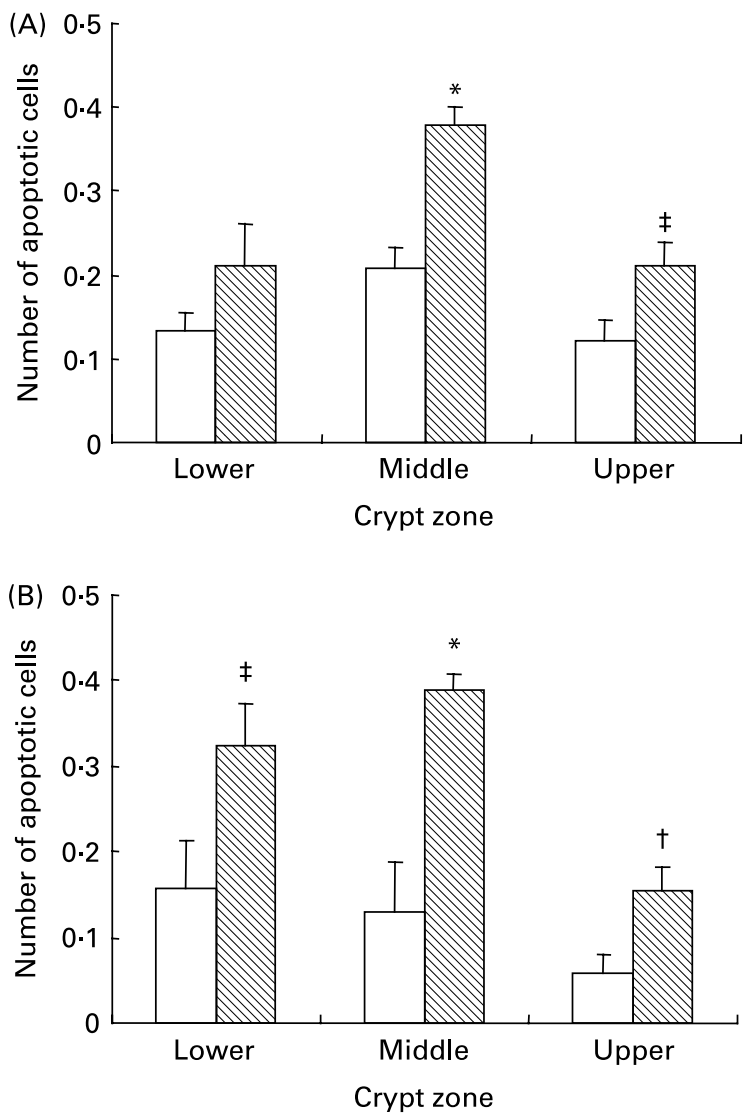

Fig. 2. Spatial distribution of apoptotic cells in crypts (forty crypts counted per colon region of rats; $n$ 6) from the mid (A) and distal (B) colon of 1,2-dimethylhydrazine ( $\mathrm{DMH})$-treated rats supplemented with propionibacteria $(\mathbb{Q}, \mathrm{PAB}+)$ or not $(\square, \mathrm{PAB}-)$. Values are means with their standard errors depicted by vertical bars. Mean values were significantly different from those of the PAB - counterpart: ${ }^{\star} P<0.01, \dagger P=0.01, \ddagger P=0.03$. 
index by immunohistochemistry. In the DMH - groups, no proliferative cells were observed in the upper zone of the crypts, as shown in Fig. 3 (A). All the proliferative cells were encountered in the lower two-thirds of the crypts. Contrastingly, DMH treatment caused an increase of the proliferative cell number localised in the upper two-thirds of the crypts, either in the mid or the distal colon. Thus, the proliferative zone extended from the bottom up to the luminal part of the crypts.

Proliferative index values were very similar between the mid and distal colon for each group, respectively (Fig. 3 (B)). In the mid colon of DMH - rats, the basal proliferative index was 56.3 (SEM 1.1 ) \% in the PAB - group and 58.3 (SEM $0.6) \%$ in the $\mathrm{PAB}+$ group. In the distal colon, it reached 56.9 (SEM 0.8) $\%$ and 57.7 (SEM 1.7) $\%$ in the PAB - and PAB+ groups, respectively.

(A)

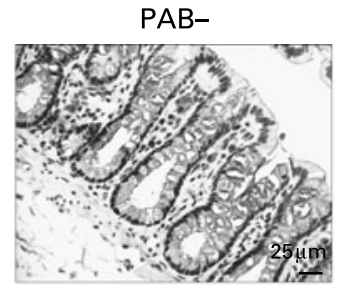

$\mathrm{DMH}+$

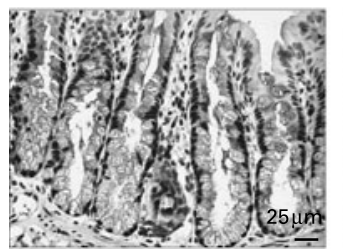

(B)

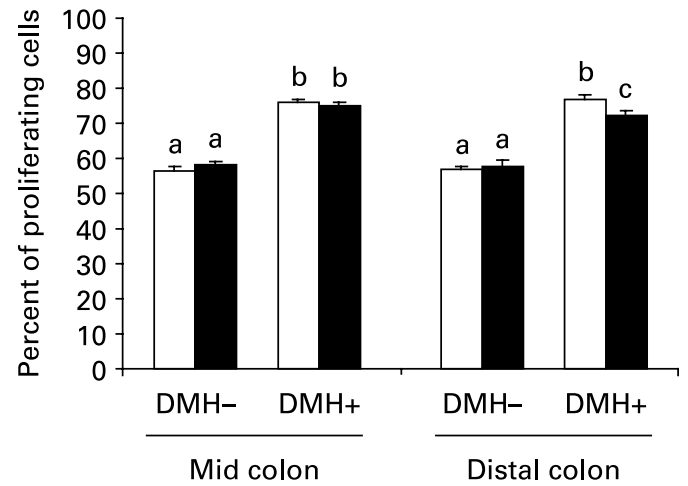

Fig. 3. Detection and quantification of proliferating cells in proliferating cell nuclear antigen and haematoxylin-stained sections of human microbiotaassociated rat colon. (A), Proliferating cells detected in distal colon crypts of rats, supplemented with propionibacteria $(\mathrm{PAB}+)$ or not $(\mathrm{PAB}-) 48 \mathrm{~h}$ after 1,2-dimethylhydrazine $(\mathrm{DMH}+)$ or saline administration $(\mathrm{DMH}-)$ (light microscope, magnification $\times 40$ ). (B), Quantification of proliferating cells per crypt (twenty crypts counted per colon region of each rat; $n 6$ ) from mid and distal colon of the same rats $(\mathbf{\square}, \mathrm{PAB}+; \square, \mathrm{PAB}-)$. Values are means with their standard errors depicted by vertical bars. Propionibacterium freudenreichii TL133 consumption resulted in a proliferative index decrease in distal colon, among the $\mathrm{DMH}+$ groups. ${ }_{\mathrm{a}, \mathrm{b}, \mathrm{c}}$ Within each colon region, values with unlike superscript letters were significantly different (ANOVA and Student-Newman-Keuls test; $P<0.01$ ).
DMH treatment induced a $20 \%$ increase of the proliferative index in both colon regions. In the mid colon, the proportion of PCNA positively labelled cells was similar in all rats: 74.9 (SEM 1.2) \% in the PAB - group v. 75.9 (SEM 0.8) \% in the $\mathrm{PAB}+$ group. In the distal colon, the administration of $\mathrm{PAB}$ significantly decreased DMH-induced proliferation; indeed, the proliferative index was 76.8 (SEM 1.2) $\%$ v. 72.1 (SEM $1.7) \%$ for the $\mathrm{PAB}-$ and $\mathrm{PAB}+$ groups, respectively $(P<0 \cdot 01)$.

\section{Discussion}

The colonic epithelium is a constantly renewing tissue, containing cells at different stages of proliferation and differentiation aligned in an orderly pattern along the crypt continuum. The sizes of the colon proliferation and maturational compartments are maintained within precise boundaries by several cell-homeostasis mechanisms, including the control of proliferation, growth arrest, differentiation and apoptosis ${ }^{(35)}$. In contrast, cancer is a disease which is characterised by an accumulation of cells that can result from either an increased proliferation or from a failure of cells to undergo apoptosis in response to appropriate stimuli ${ }^{(36)}$. One mechanism by which suppressing agents might act is by inducing previously initiated cells to follow the apoptotic pathway, causing their deletion from the tissue and thus preventing clonal expansion of the neoplastic lesion ${ }^{(37)}$. With the aim of evaluating the potential of $P$. freudenreichii as such a suppressing agent, we used a well-known model of DMH-induced colon carcinogenesis in HMA rats. HMA rats constitute a now well-validated model for experimental studies aimed at evaluating the effects of functional foods, including probiotics, in gastrointestinal physiology $y^{(38-41)}$. The impact of a food component may depend on its utilisation or modification by the resident intestinal microbiota. Moreover, the activity of a probiotic may be modulated by the presence of this microbiota. HMA rats were previously used to evidence the adaptation of $P$. freudenreichii TL133 and its metabolic activity within the intestine, taking into account both the presence of a human colonic microbiota and its modulation by the probiotic ${ }^{(26)}$. $\mathrm{DMH}$-induced tumourigenesis in the rat colon is a prolonged multistage process, which shares many of the kinetic, histopathological and molecular characteristics of tumourigenesis in the human colon $^{(42)}$.

To study the potential protective effects of $P$. freudenreichii TL133 strain on apoptosis and on the proliferation of colonic mucosa at an early stage of carcinogenesis, we used a $48 \mathrm{~h}$ exposure to DMH before killing, as described previously ${ }^{(43)}$. Indeed, administration of the carcinogen leads to an immediate inhibition of mitosis associated with an acute apoptotic response, detected as soon as $6 \mathrm{~h}$ after DMH treatment and which may last up to $5 \mathrm{~d}$ in the rodent colonic crypt $^{(44,45)}$. Before exposure to the carcinogen, rats were gavaged with $P$. freudenreichii TL133 for $12 \mathrm{~d}$ in order for them to attain a steadily high and metabolically active propionibacterial population in the gastrointestinal tract.

In the present study, we demonstrated the ability of $P$. freudenreichii TL133 to increase apoptosis of DMH-damaged cells at an early stage of malignant transformation in HMA rats. Considering that $\mathrm{DMH}$ treatment induces pre-neoplastic lesions in the mid and distal regions of the colon ${ }^{(46)}$, we did 
not investigate apoptosis and proliferation in the proximal region. In both mid and distal colonic regions, $P$. freudenreichii significantly enhanced the apoptotic death of DMHdamaged epithelial cells. The observed increase in apoptosis was similar in magnitude to that previously reported by Smith et al. ${ }^{(23)}$ in the mid colon of rats fed with sinigrin after the same time of treatment with DMH. However, they, as well as Latham et al. ${ }^{(21)}$, reported a smaller number of apoptotic cells in the distal region compared to that found in the mid region in conventional rats, a difference that we did not observe in HMA rats. In these aforementioned studies, apoptosis was quantified using morphological criteria, while in the present study it was assessed using the TUNEL method, which does not allow for the detection of cells at early stages of apoptosis, before the occurrence of DNA fragmentation. Therefore, apoptosis could have been underestimated in the present study. On the other hand, the TUNEL method may detect necrotic cells containing damaged $\mathrm{DNA}^{(47)}$ but no typical sign of necrosis, such as inflammation, was observed in the colon of the rats used in the present study. We also assessed the distribution of apoptotic cells within the colonic crypt. In a healthy colon, $80 \%$ of apoptosis takes place at the upper third of the crypt, none at its middle and rarely, if ever, in the basal region ${ }^{(48)}$. In contrast, in DMHtreated rats, the administration of PAB increased the number of apoptotic cells in all crypt zones but particularly in the lower and middle parts, where normally apoptosis does not occur. Similarly, other protective compounds increase DMHinduced apoptosis in the lower parts of the crypt ${ }^{(21,23)}$. Stem cells, which are especially sensitive to treatment with carcinogens, are located in these parts. PAB-induced apoptosis could specifically target cells mutated by carcinogens. Indeed, no sign of apoptosis was observed in the presence of PAB alone. Furthermore, in rats treated with $\mathrm{DMH}$, we observed an increase of the proliferative index in the upper zone of the crypt, that is to say in the differentiation zone, where proliferation normally does not occur. Potten ${ }^{(48)}$ reported that exposure to a chemical carcinogen leads to an immediate inhibition of mitosis, followed by a recovery, which is often associated with a displacement of mitosis to the upper region of the crypt. Proliferating cells were detected using PCNA immunolabelling. This protein has been reported to be stable and $30-40 \%$ of its total initial amount remains present after $24 \mathrm{~h}$ of quiescence in $3 \mathrm{~T} 3$ cells $^{(49)}$. This may have led to an overestimation of the number of proliferating cells in the present study. However, PCNA labelling evidenced a decrease in proliferation in DMH-treated rats as a result of the consumption of a bifidobacteria-oligofructose combination $^{(34)}$ and in azoxymethane-treated rats as a result of consumption of an inulin-raftilose combination ${ }^{(50)}$.

In our previous in vitro studies, the proposed mechanism of apoptosis induction by PAB was a direct action of SCFA, including propionate, on cancer cells ${ }^{(24,25)}$. However, in the present in vivo study, the caecal concentrations of SCFA, which were close to those determined in our previous study using the same $\mathrm{PAB}$ in the same model ${ }^{(26)}$, exhibited no marked differences between groups. Dairy PAB adhere to intestinal epithelial cells ${ }^{(51,52)}$. This contact is likely to result in a local action of propionibacterial pro-apoptotic metabolites on colonocytes, without measurable accumulation in the caecal content. In that respect, it is noteworthy that some $P$. freudenreichii strains have been shown to produce nitric oxide ${ }^{(53)}$, known to be an inducer of apoptosis ${ }^{(54)}$, in addition to SCFA.

\section{Conclusion}

P. freudenreichii TL133, a probiotic bacterium previously shown to induce apoptosis of cancer cells in vitro, was shown here for the first time to induce apoptosis of colon cells in vivo. The induction of apoptosis occurred only in animals treated with $\mathrm{DMH}$, suggesting that this induction specifically targets damaged cells. Altogether, the present data indicate that dairy PAB may help in the elimination of damaged cells by apoptosis within the colon epithelium. This suggests a protective role against colon cancer, which should be further confirmed by in vivo carcinogenesis longterm assays aimed at determining their effect on colorectal tumour incidence.

\section{Acknowledgements}

The authors acknowledge A. Bouclet (UR910 Ecologie et Physiologie du Système Digestif, Jouy-en-Josas, France) and S. Parayre (UMR1253 Science et Technologie du Lait et de l'Oeuf, Rennes, France) for technical assistance as well as Dr A. S. de Lajarte-Thirouard for her expertise in morbid anatomy. The authors thank John McCulloch for revising and correcting the English language. This work has been supported by a grant from CRITT Santé Bretagne. A. L. was the recipient of a doctoral fellowship, 50\% from INRA and 50\% from the company Laboratoires Standa. A. B. and M. B. participated with A. L. in microbiological analysis and in animal handling, killing and dissection, and with C. P. in SCFA analysis. P. B. trained A. L. in morbid anatomy and histology. S. R. designed and supervised the study and performed the statistical analysis and G. J. supervised the PhD thesis. The authors declare no conflicts of interest.

\section{References}

1. Giovannucci E (2002) Modifiable risk factors for colon cancer. Gastroenterol Clin North Am 31, 925-943.

2. Martinez ME (2005) Primary prevention of colorectal cancer: lifestyle, nutrition, exercise. Recent Results Cancer Res 166, $177-211$

3. Cummings JH \& Bingham SA (1998) Diet and the prevention of cancer. Br Med J 317, 1636-1640.

4. Food and Agriculture Organization of the United Nations and World Health Organization (2002) Guidelines for the Evaluation of Probiotics in Food. FAO/WHO Working Group Report. Geneva: FAO/WHO.

5. Arimochi H, Kinouchi T, Kataoka K, Kuwahara T \& Ohnishi Y (1997) Effect of intestinal bacteria on formation of azoxymethane-induced aberrant crypt foci in the rat colon. Biochem Biophys Res Commun 238, 753-757.

6. Bolognani F, Rumney CJ, Pool-Zobel BL \& Rowland IR (2001) Effect of lactobacilli, bifidobacteria and inulin on the formation of aberrant crypt foci in rats. Eur J Nutr 40, 293-300.

7. Goldin BR, Gualtieri LJ \& Moore RP (1996) The effect of Lactobacillus GG on the initiation and promotion of DMHinduced intestinal tumors in the rat. Nutr Cancer 25, 197-204. 
8. Marotta F, Naito Y, Minelli E, et al. (2003) Chemopreventive effect of a probiotic. Preparation on the development of preneoplastic and neoplastic colonic lesions: an experimental study. Hepato-gastroenterology 50, 1914-1918.

9. McIntosh GH, Royle PJ \& Playne MJ (1999) A probiotic strain of L-acidophilus reduces DMH-induced large intestinal tumors in male Sprague-Dawley rats. Nutr Cancer 35, 153-159.

10. Yamazaki K, Tsunoda A, Sibusawa M, et al. (2000) The effect of an oral administration of Lactobacillus casei strain Shirota on azoxymethane-induced colonic aberrant crypt foci and colon cancer in the rat. Oncol Rep 7, 977-982.

11. Wollowski I, Rechkemmer G \& Pool-Zobel BL (2001) Protective role of probiotics and prebiotics in colon cancer. Am J Clin Nutr 73, 451S-455S.

12. Hirayama K \& Rafter J (2000) The role of probiotic bacteria in cancer prevention. Microbes Infect 2, 681-686.

13. Commane D, Hughes R, Shortt C \& Rowland I (2005) The potential mechanisms involved in the anti-carcinogenic action of probiotics. Mut Res 591, 276-289.

14. Rafter J (2003) Probiotics and colon cancer. Best Pract Res Clin Gastroenterol 17, 849-859.

15. Hanahan D \& Weinberg RA (2000) The hallmarks of cancer. Cell 100, 57-70.

16. Bedi A, Pasricha PJ, Akhtar AJ, et al. (1995) Inhibition of apoptosis during development of colorectal cancer. Cancer Res 55, $1811-1816$.

17. Baretton GB, Diebold J, Christoforis G, et al. (1996) Apoptosis and immunohistochemical bcl-2 expression in colorectal adenomas and carcinomas - aspects of carcinogenesis and prognostic significance. Cancer 77, 255-264.

18. Moss SF, Scholes JV \& Holt PR (1996) Abnormalities of epithelial apoptosis in multistep colorectal neoplasia demonstrated by terminal deoxyuridine nick end labeling. Dig Dis Sci 41, $2238-2247$.

19. Anti M, Armuzzi A, Morini S, et al. (2001) Severe imbalance of cell proliferation and apoptosis in the left colon and in the rectosigmoid tract in subjects with a history of large adenomas. Gut 48, 238-246.

20. Hughes R \& Rowland IR (2001) Stimulation of apoptosis by two prebiotic chicory fructans in the rat colon. Carcinogenesis 22, 43-47.

21. Latham P, Lund EK \& Johnson IT (1999) Dietary $n$-3 PUFA increases the apoptotic response to 1,2-dimethylhydrazine, reduces mitosis and suppresses the induction of carcinogenesis in the rat colon. Carcinogenesis 20, 645-650.

22. Le Leu RK, Brown IL, Hu Y, et al. (2005) A synbiotic combination of resistant starch and Bifidobacterium lactis facilitates apoptotic deletion of carcinogen-damaged cells in rat colon. J Nutr 135, 996-1001.

23. Smith TK, Lund EK \& Johnson IT (1998) Inhibition of dimethylhydrazine-induced aberrant crypt foci and induction of apoptosis in rat colon following oral administration of the glucosinolate sinigrin. Carcinogenesis 19, 267-273.

24. Jan G, Belzacq AS, Haouzi D, et al. (2002) Propionibacteria induce apoptosis of colorectal carcinoma cells via short-chain fatty acids acting on mitochondria. Cell Death Differ 9, 179-188.

25. Lan A, Lagadic-Gossmann D, Lemaire C, Brenner C \& Jan G (2007) Acidic extracellular $\mathrm{pH}$ shifts colorectal cancer cell death from apoptosis to necrosis upon exposure to propionate and acetate, major end-products of the human probiotic propionibacteria. Apoptosis 12, 573-591.

26. Lan A, Bruneau A, Philippe C, et al. (2007) Survival and metabolic activity of selected strains of Propionibacterium freudenreichii in the gastrointestinal tract of human microbiotaassociated rats. Br J Nutr $\mathbf{9 7}, 714-724$.

27. Coates ME (1968) The Germ-free Animal in Research. New York: Academic Press.
28. Caderni G, Giannini A, Lancioni L, Luceri C, Biggeri A \& Dolara P (1995) Characterisation of aberrant crypt foci in carcinogen-treated rats: association with intestinal carcinogenesis. Br J Cancer 71, 763-769.

29. Hambly RJ, Saunders M, Rijken PJ \& Rowland IR (2002) Influence of dietary components associated with high or low risk of colon cancer on apoptosis in the rat colon. Food Chem Toxicol 40, 801-808.

30. Jan G, Leverrier P \& Roland N (2002) Survival and beneficial effects of propionibacteria in the human gut: in vivo and in vitro investigations. Lait 82, 131-144.

31. Rabot S, Szylit O, Nugon-Baudon L, et al. (2000) Variations in digestive physiology of rats after short duration flights aboard the US space shuttle. Dig Dis Sci 45, 1687-1695.

32. Gavrieli Y, Sherman Y \& Ben-Sasson SA (1992) Identification of programmed cell death in situ via specific labeling of nuclear DNA fragmentation. J Cell Biol 119, 493-501.

33. Hall PA, Levison DA, Woods AL, et al. (1990) Proliferating cell nuclear antigen (PCNA) immunolocalization in paraffin sections: an index of cell proliferation with evidence of deregulated expression in some neoplasms. J Pathol 162, 285-294.

34. Gallaher DD \& Khil J (1999) The effect of synbiotics on colon carcinogenesis in rats. $J$ Nutr 129, 1483 S-1487S.

35. Davenport HW (1977) Physiology of the Digestive Tract, 4th ed. Chicago: Year Book Medical Publishers.

36. Tsujitani S, Shirai H, Tatebe S, et al. (1996) Apoptotic cell death and its relationship to carcinogenesis in colorectal carcinoma. Cancer 77, 1711-1716.

37. Johnson IT (2002) Anticarcinogenic effects of diet-related apoptosis in the colorectal mucosa. Food Chem Toxicol 40, $1171-1178$.

38. Djouzi Z, Andrieux C, Degivry MC, Bouley C \& Szylit O (1997) The association of yogurt starters with Lactobacillus casei DN 114.001 in fermented milk alters the composition and metabolism of intestinal microflora in germ-free rats and in human flora-associated rats. J Nutr 127, 2260-2266.

39. Humblot C, Lhoste E, Knasmuller S, et al. (2004) Protective effects of Brussels sprouts, oligosaccharides and fermented milk towards 2-amino-3-methylimidazo[4,5-f]quinoline (IQ)induced genotoxicity in the human flora associated F344 rat: role of xenobiotic metabolising enzymes and intestinal microflora. J Chromatogr B Analyt Technol Biomed Life Sci 802, $231-237$

40. Imaoka A, Setoyama H, Takagi A, Matsumoto S \& Umesaki Y (2004) Improvement of human faecal flora-associated mouse model for evaluation of the functional foods. $J$ Appl Microbiol 96, 656-663.

41. Kleessen B, Hartmann L \& Blaut M (2001) Oligofructose and long-chain inulin: influence on the gut microbial ecology of rats associated with a human faecal flora. $B r J$ Nutr 86, 291-300.

42. Nigro ND (1985) Animal model for colorectal cancer. Prog Clin Biol Res 186, 161-173.

43. Smith TK, Mithen R \& Johnson IT (2003) Effects of Brassica vegetable juice on the induction of apoptosis and aberrant crypt foci in rat colonic mucosal crypts in vivo. Carcinogenesis 24, 491-495.

44. Ijiri K (1989) Apoptosis (cell death) induced in mouse bowel by 1,2-dimethylhydrazine, methylazoxymethanol acetate, and gamma-rays. Cancer Res 49, 6342-6346.

45. Sunter JP, Watson AJ \& Appleton DR (1981) Kinetics of the non-neoplastic mucosa of the large bowel of dimethylhydrazine-treated rats. Br J Cancer 44, 35-44.

46. Carter JW, Lancaster HK, Hardman WE \& Cameron IL (1994) Distribution of intestine-associated lymphoid tissue, aberrant crypt foci, and tumors in the large bowel of 1,2-dimethylhydrazine-treated mice. Cancer Res 54, 4304-4307. 
47. Riss TL (2001) Apoptosis as a biomarker in chemoprevention trials. Urology 57, 141-142.

48. Potten CS (1992) The significance of spontaneous and induced apoptosis in the gastrointestinal tract of mice. Cancer Metastasis Rev 11, 179-195.

49. Bravo R \& Donald-Bravo H (1987) Existence of two populations of cyclin/proliferating cell nuclear antigen during the cell cycle: association with DNA replication sites. $J$ Cell Biol 105, 1549-1554.

50. Femia AP, Luceri C, Dolara P, et al. (2002) Antitumorigenic activity of the prebiotic inulin enriched with oligofructose in combination with the probiotics Lactobacillus rhamnosus and Bifidobacterium lactis on azoxymethane-induced colon carcinogenesis in rats. Carcinogenesis 23, 1953-1960.
51. Huang Y \& Adams MC (2003) An in vitro model for investigating intestinal adhesion of potential dairy propionibacteria probiotic strains using cell line C2BBe1. Lett Appl Microbiol 36, 213-216.

52. Zarate G, Morata D, Chaia AP \& Gonzalez SN (2002) Adhesion of dairy propionibacteria to intestinal epithelial tissue in vitro and in vivo. J Food Prot 65, 534-539.

53. Avice JC, Ourry A, Laine P, et al. (1999) A rapid and reliable method for $\mathrm{NO}$ quantification and ${ }^{15} \mathrm{NO} /{ }^{14} \mathrm{NO}$ determination using isotope ratio mass spectrometry: an application for the detection of NO synthesis in propionibacteria. Rapid Commun Mass Spectrom 13, 1197-1200.

54. Monteiro HP, Silva EF \& Stern A (2004) Nitric oxide: a potential inducer of adhesion-related apoptosis-anoikis. Nitric Oxide 10, $1-10$. 